\title{
Avaliando a capacidade de governo: reflexões sobre a experiência do Prêmio "Municípios que Fazem Render Mais" (2010 e 2011)
}

\author{
Francisco Fonseca \\ Escola Brasileira de Administração Pública e de Empresas (EAESP/FGV) \\ Ricardo Ernesto Vasquez Beltrão \\ Escola Brasileira de Administração Pública e de Empresas (EAESP/FGV) \\ Otávio Prado \\ Escola Brasileira de Administração Pública e de Empresas (EAESP/FGV)
}

\begin{abstract}
Este artigo analisa conceitualmente a experiência do Prêmio "Municípios que Fazem Render Mais", desenvolvido por pesquisadores do Centro de Estudos em Administração Pública e Governo da Fundação Getulio Vargas de São Paulo, em dois momentos: nos estados do Sul em 2010 e no estado de São Paulo em 2011. A partir do conceito de "triângulo de governo", desenvolvido por Carlos Matus em seu construto sobre o Planejamento Estratégico Situacional (PES), analisa-se especialmente a "capacidade de governo" - um dos vértices do triângulo — dos municípios inscritos no Prêmio. O artigo descreve os pressupostos que informam o Prêmio, assim como os critérios e a metodologia adotados, e reflete sobre as escolhas realizadas para premiar os municípios ao analisar os desafios que representa avaliar gestões municipais. Por fim, o artigo analisa especificamente os municípios paulistas, o que implica estabelecer parâmetros para a comparação de contextos e gestões bastante distintos.
\end{abstract}

Palavras-chave: capacidade de governo; Prêmio "Municípios que Fazem Render Mais"; gestão municipal; avaliação da gestão; comparação entre gestões.

Evaluación de la capacidad de gobierno: reflexiones sobre la experiencia del Premio "Municípios que Fazem Render Mais" (2010 e 2011)

En este artículo examina conceptualmente la experiencia del Premio "Municípios que Fazem Render Mais", desarrollado por investigadores del Centro de Estudos em Administração Pública e Governo de la Fundação Getulio Vargas de São Paulo, en dos etapas: en los estados del Sur en 2010 y en el estado de São Paulo en 2011. Desde el concepto de "triángulo de gobierno", desarrollado por Carlos Matus en su construcción de Planificación Estratégica Situacional (PES), analiza especialmente la "capacidad de gobernar" - uno de los vértices del triángulo - en los municipios incluidos en el premio. El artículo

Artigo recebido em 27 ago. 2012 e aceito em 15 nov. 2012.

Rev. Adm. Pública - Rio de Janeiro 47(1):249-272, jan./fev. 2013 
describe los supuestos que informan al premio, así como los criterios y la metodología adoptados, y reflexiona sobre las decisiones tomadas para recompensar a los municipios para analizar los retos de la evaluación de las administraciones municipales. Por último, el artículo analiza especificamente los municipios de São Paulo, lo que implica el establecimiento de parámetros para la comparación de contextos y gestiones muy distintas.

Palabras clave: capacidad del gobierno; Premio "Municípios que Fazem Render Mais"; gestión municipal; evaluación de la gestión; comparación entre administraciones.

Assessing the government capacity: reflections on the experience Award "Municipalities that Make More Render" (2010 and 2011)

This article examines conceptually the experience Award "Municipalities that Make More Render", developed by researchers at the Center for Studies in Public Administration and Government of the Getulio Vargas Foundation in São Paulo, in two stages: in the Southern states in 2010 and in the state of São Paulo in 2011. From the concept of "triangle of government," developed by Carlos Matus in his construct of the Strategic Situational Planning analyzes especially the "capacity to govern" - one of the vertices of the triangle - the municipalities included in the Award. The article describes the assumptions that inform the Award, as well as the criteria and methodology adopted, and reflects on the choices made to reward municipalities to analyze the challenges of evaluating municipal administrations. Finally, the article analyzes specific counties, which implies establishing parameters for comparing very different contexts and managements.

KEY words: government capacity; Award "Municipalities that Make More"; municipal management; management evaluation; comparing managements.

\section{Introdução}

O Prêmio "Municípios que Fazem Render Mais" surgiu da inquietação de setores empresariais, inicialmente do sul do país, por meio da Associação Comercial e Industrial de Joinville (Acij), em 2010, e depois no estado de São Paulo, pela Federação das Indústrias do Estado de São Paulo (Fiesp), em relação ao papel e aos impactos da gestão pública nos municípios. No caso dos estados do Sul, o Instituto Brasileiro de Economia (Ibre) da FGV foi procurado para desenvolvê-lo, mas, em razão da expertise (acadêmica e aplicada) do Centro de Estudos em Administração Pública e Governo (CEAPG) da FGV/Eaesp, este foi indicado, pelo próprio Ibre, para conduzir o prêmio. Tal condução referiu-se à concepção do prêmio e à definição de seus objetivos, metodologia e procedimentos (formais, técnicos e legais). Coube, portanto, ao CEAPG, tendo em vista sua experiência histórica na condução do Prêmio "Gestão Pública e Cidadania" - experiência na qual o "Prêmio Municípios que Fazem Render Mais" se inspirou parcialmente - , conceber e aplicar empiricamente aos municípios os critérios elaborados.

É importante esclarecer dois aspectos fundamentais: a) tanto na edição do Sul como na de São Paulo, o CEAPG teve total autonomia para conceber e executar o prêmio, sem qualquer ingerência dos patrocinadores em quaisquer de suas etapas, pois se limitaram, contratualmen- 
te, ao patrocínio dos custos e à divulgação do prêmio; e b) a diferença entre o Prêmio "Gestão Pública e Cidadania" e o Prêmio "Municípios que Fazem Render Mais" se refere aos objetivos, uma vez que o primeiro avaliava "programas específicos" de um dado órgão de governo (da administração direta e indireta) e o segundo voltou-se à "avaliação da gestão" como um todo dos municípios.

Nesse sentido, avaliar gestões públicas municipais implica grandes desafios, em si e para o CEAPG, em razão da aludida tradição de avaliação de programas específicos e não de gestões. Isso significou esforço teórico e metodológico sem precedentes: daí a necessidade de criação de novos critérios e categorias resultantes de escolhas teórico-metodológicas claras e aplicáveis, sobretudo em contextos de desigualdades históricas e referentes ao federalismo e ao financiamento municipal via-à-vis as novas competências advindas da Constituição de 1988, entre outras.

É nesse sentido que o construto teórico-metodológico advindo do Planejamento Estratégico Situacional (PES) foi a inspiração das escolhas adotadas no Prêmio "Municípios que Fazem Render Mais". Embora o método PES refira-se ao planejamento governamental e o objetivo do Prêmio volte-se à avaliação de gestões públicas — objetivos distintos, portanto o construto teórico do PES contribuiu para que se pudessem enfrentar os desafios teóricos e empíricos da avaliação de governos. Em particular por meio de seu conhecido triângulo de governo, em que Carlos Matus (2006:130) procura observar "a situação de um governante perante a realidade", a capacidade de governo surge como um dos três vértices que correspondem às variáveis-chave a serem consideradas na análise de êxito de governos (os outros dois vértices são o "projeto de governo" e a "governabilidade"). De forma sintética, uma vez que o método PES é sobejamente conhecido, segundo Matus:

Esse triângulo sintetiza a situação de um governante perante a realidade. As três variáveis ( $\mathrm{B}, \mathrm{B}$ e $\alpha$ ) dão forma ao sistema. A baixa capacidade de governo afeta a governabilidade, a qualidade da proposta e a gestão do governo. As exigências do projeto de governo põem em prova a capacidade de governo e a governabilidade do sistema. A governabilidade do sistema, por fim, impõe limites ao projeto de governo e faz exigências à capacidade de governo (Matus, 2006:130).

Em outras palavras, em uma situação de incerteza quanto a vários aspectos (econômicos, políticos, sociais, internacionais etc.), os governos necessitariam diminuir as variáveis que não controlam e aumentar as que controlam: daí o papel da técnica e da política, conjugadas.

Mas o construto que tem na capacidade de governo seu elemento-chave poderia ser também utilizado para compreender, em perspectiva comparada, os diferentes contextos (isto é, situações econômico/sociais) nos quais os governos atuam? Tendo como hipótese que sim, este artigo objetiva refletir preliminarmente a respeito da capacidade de governo e consequentemente de governar à luz da experiência vivenciada nas duas edições do Prêmio "Municípios que Fazem Render Mais", numa perspectiva ao mesmo tempo conceitual e empírica. 
Quanto à estrutura do texto, além da Introdução, na segunda seção são apresentados os objetivos e a forma de execução do Prêmio, o que significa expor as escolhas realizadas. Na terceira seção são apresentados os indicadores que foram considerados no Prêmio para subsidiar a análise dos diferentes contextos nos quais os governos municipais atuam a partir das dimensões econômica, social e de gestão municipal, que conformam importantes diferenças quanto a esses contextos. Na quarta seção procurou-se evidenciar alguns dos contrastes, entre os municípios paulistas, relativos a essas três dimensões, considerando o porte populacional e as regiões administrativas nas quais estão localizados. Nas "considerações finais" sintetiza-se a discussão desenvolvida e, sobretudo, se expõe a agenda de problemas que o Prêmio ensejou.

\section{0 Prêmio "Municípios que Fazem Render Mais"}

Desenvolvido por pesquisadores ligados ao CEAPG, o Prêmio "Municípios que Fazem Render Mais" vem se consolidando, conceitual e empiricamente. Conforme previsto em seu Regulamento,

O Prêmio "Municípios que Fazem Render Mais" objetiva identificar, reconhecer, e disseminar práticas de bom uso dos recursos públicos pelos municípios, valorizando assim os esforços voltados à melhoria da capacidade de planejamento e gestão, à democratização, e à prestação de serviços de qualidade aos cidadãos (Regulamento, item 1.1, ênfases nossas, disponível em: <www.fiesp. com.br/premio-municipios/regulamento.asp $>$ ).

O Prêmio procurou — em suas duas edições — avaliar os seguintes aspectos da gestão municipal:

- A capacidade de o município institucionalizar suas ações em prol da democratização, da transparência, da eficiência e da efetividade no uso dos recursos públicos. Para tanto, seja a institucionalização legal (aprovação de leis), seja a legitimação social, por meio de fóruns diversos, foram os mecanismos observáveis;

、 A demonstração de que há transparência da gestão pública por meio da publicização de dados, informações, contratos públicos e do uso do dinheiro público como um todo, por meios diversos. Aqui, as restrições e potencialidades de cada município são tomadas como particularidades a serem observadas;

v A abertura à participação dos cidadãos nas decisões governamentais, por canais diversos, tais como participação no orçamento, audiências públicas, o que contempla uma ampla gama de inovações sociais e institucionais;

v A contribuição da administração municipal ao desenvolvimento local, tal como o apoio ao investimento privado (de portes distintos), sobretudo local, por variadas formas, o que implica, como ponto de partida, a existência de estrutura institucional e prioridade governamental; 
v A conjugação entre responsabilidade fiscal e responsabilidade social: entendida a primeira como respeito à "Lei de Responsabilidade Fiscal" e a segunda como a existência de metas sociais (em áreas como educação, saúde, assistência social) a serem obtidas, tendo-se como parâmetros indicadores sociais consolidados, a começar pelos regionais.

Como se observa, trata-se de um conjunto amplo e variado de macrocritérios cujo objetivo é justamente obter elementos acerca da gestão municipal em diversas dimensões, retratando ao máximo o conjunto do governo e de suas ações — sem a pretensão de esgotar sua compreensão - , o que implica, contudo, enormes desafios, de ordem conceitual e operacional.

Em termos conceituais, a indagação-chave é: por que essas dimensões e não outras? Aqui o "triângulo do governo" é o pressuposto referencial, como dissemos, uma vez que as dimensões escolhidas estão muito mais voltadas ao âmbito das ações possíveis e dependentes da capacidade de governo (ou da virtú, na linguagem de Maquiavel) do que dos aspectos indeterminados da realidade, embora esses sejam um permanente e indefinível vetor. Mas, mesmo as incertezas poderiam ser, em boa medida, diminuídas pela ação governamental, notadamente por meio do planejamento.

Mais ainda, as dimensões escolhidas são inteiramente condizentes: a) ao "éthos cidadão" da Constituição Federal (transparência quanto ao uso dos recursos e decisões públicos; apoio à participação popular; e conjugação inextricável entre preceitos fiscais e sociais); b) ao papel do poder público como elemento dinamizador local (apoio ao desenvolvimento, em diversos sentidos, local e regional); e c) à perenidade das ações, por meio de sua institucionalização — legalidade e legitimidade social —, isto é, políticas públicas, programas e ações que se edificam como "políticas de Estado", superando a fugacidade e a vulnerabilidade das "políticas de governo".

Do ponto de vista operacional, deve-se ressaltar que examinar empiricamente ações e programas municipais que compõem a gestão exige o cotejamento das informações prestadas pelas prefeituras com as avaliações elaboradas pela equipe do Prêmio. Aqui, abre-se uma ampla agenda de questões relacionadas à etnografia do campo; à relação entre roteiro de pesquisa e sensibilidade dos pesquisadores; às dificuldades orçamentárias e de seleção dos pesquisadores; à audição de vozes destoantes dos governos pesquisados, cuja detecção é por vezes difícil, sem contar o escasso período de visita ao município; entre outras questões relevantes.

A premiação procurou avançar na seleção, coleta e cruzamento de indicadores públicos, sobretudo na edição paulista. Tais indicadores deram à pesquisa — ressalte-se que a premiação implica pesquisa - um quadro macro dos limites e potencialidades dos municípios quanto à sua capacidade de governo, sobretudo do ponto de vista orçamentário e social.

No entanto, esse quadro macro de indicadores, utilizado particularmente pelos julgadores dos Comitês Técnicos compostos por professores, pesquisadores e especialistas e gestão pública, é subsídio que pode, ou não, ser invocado, de formas diversas e com pesos distintos: tratou-se de um balizamento que foi melhorado de uma edição a outra e tende a 
ganhar, numa próxima edição, peso ainda maior do que teve. Do ponto de vista metodológico, a utilização de indicadores objetivou apenas e tão somente dar informações quantitativas aos membros do Comitê, sem obrigá-los a segui-las, uma vez que a experiência de cada um de seus membros foi o aspecto crucial para o modelo metodológico da pesquisa que subsidiou o Prêmio. Já os pesquisadores de campo tinham como foco a avaliação in loco da gestão.

Aspectos diversos contribuíram para tanto, tais como a liberdade que os membros dos Comitês Técnicos tiveram para julgar; quais indicadores deveriam fazer parte da cesta de dados, pois existem "n" disponíveis; qual grau de priorização deveria ser dado no tocante à tomada de decisão do julgador e mesmo à orientação dos pesquisadores de campo; entre outros. Apesar dessas questões em aberto, e que possivelmente só serão resolvidas com edições sucessivas do Prêmio, reitere-se o avanço que se obteve com a criação e o cruzamento de indicadores. Além disso, consultas aos sítios das prefeituras e do Tribunal de Contas Estadual e a averiguação de todas as informações chegadas à coordenação do Prêmio - mesmo que informalmente - procuraram aprofundar a compreensão da gestão municipal.

Quanto às escolhas dos critérios adotados, é claro que outros poderiam ser feitos, dependendo do enfoque que se queira observar. Optou-se no Prêmio por critérios advindos da Constituição Federal, mas, sobretudo, dos seguintes pressupostos conceituais: gestão democrática (participação e transparência) e cidadã (inclusão política e social); separação entre as esferas pública e privada, embora se podendo utilizar parcerias entre organizações públicas e não estatais; conexão entre a relação dos meios (gestão) com os fins (políticas públicas e ações governamentais finalísticas); equilíbrio entre responsabilidade com as finanças e com a sociedade (nessa última, sobretudo o combate à pobreza e a promoção da justiça social); preocupação em tornar as políticas públicas longevas, institucionalizadas como "de Estado". Trata-se, portanto, de um conjunto de escolhas, cujos pressupostos se referem à democracia social, em termos conceituais e empíricos.

Nesse sentido, deve-se notar que, embora a democracia tenha originalmente uma conceituação política, como regime de regulação de conflitos e de participação, desde o final do século XIX vem continuamente expandindo seu campo de atuação às áreas sociais, isto é, a instauração no chamado estado de bem-estar social. Assim, o moderno conceito de democracia implica considerá-la democracia social.

Voltando ao Prêmio, é necessário esclarecer que a utilização dessas informações e dados nas várias etapas do Prêmio não objetivou classificar ou desclassificar os municípios participantes. O intuito foi tão somente fornecer subsídios aos membros do Comitê Técnico responsável pela escolha dos municípios em cada etapa do processo, de forma a que pudesse identificar diferenças quanto ao contexto socioeconômico e de gestão nos quais os distintos governos municipais atuam.

A única forma pela qual o Prêmio diferenciou preliminarmente os municípios foi quanto a seu porte populacional, definindo-se três categorias (até 50 mil, mais de 50 mil e até 250 mil e mais de 250 mil habitantes). Dessa forma, em cada etapa do processo de escolha, o Comitê Técnico foi subdividido por categoria que — à luz das informações prestadas pelos próprios 
municípios, por meio de questionários, e com o apoio de indicadores e dados organizados pela Equipe do Prêmio - pôde escolher os municípios para a etapa subsequente.

Esses procedimentos foram fundamentais, tendo em vista o pressuposto adotado: diante das enormes diferenças de contexto nos quais atuam os governos municipais, não caberia ao Prêmio predefinir o que seria "fazer render mais". Assim, ao participarem voluntariamente do processo, coube exclusivamente aos governantes municipais expressarem sua própria percepção do que seria "fazer render mais" pela demonstração de evidências condensadas por programas e ações que estivessem desenvolvendo. Tais percepções dar-se-iam, contudo, dentro do amplo leque de macrocritérios estabelecidos pelo Prêmio e foi na busca de identificar os indicadores possíveis que o Prêmio traz talvez sua contribuição maior: como comparar diferentes contextos municipais, como usar informações publicamente disponíveis para discutir gestão.

Note-se que os principais desafios do Prêmio dizem respeito à identificação de práticas de bom uso dos recursos públicos e da gestão pública (ambos em sentido lato), e não à mensuração de desempenhos. Como toda tentativa de leitura da realidade implica reducionismo, o Prêmio procurou adotar instrumentos que permitissem enxergar as administrações a partir de múltiplos ângulos.

\section{Em busca de indicadores para a comparação dos diferentes contextos municipais}

A partir dos pressupostos e objetivos do Prêmio, vistos anteriormente, discutiremos agora o papel dos indicadores como forma de compreender os municípios em seus contextos.

Dessa forma, as históricas formas de desigualdade envolvem contextos socioeconômicos distintos em que o governante atua ao ser eleito, bem como a "acumulação de perícia" para a gestão dos aparatos burocráticos, que depende, por seu turno, do domínio da legislação, do orçamento, da estrutura administrativa, dos recursos humanos, entre outros.

É verdade que o período pós-1988 vem sendo marcado por importantes avanços quanto à institucionalidade jurídica e fiscal no sentido de mitigar muitas dessas assimetrias. Não faltam exemplos das formas pelas quais a federação brasileira vem buscando proporcionar maior reforço aos caixas municipais pela via das transferências intergovernamentais conforme os municípios expandem sua atuação em áreas como ensino, saúde, assistência social, habitação. Apesar desse processo, que implica avanços à descentralização municipal, o país está distante da efetiva superação das profundas assimetrias quanto às condições materiais, orçamentárias e humanas para a gestão dos municípios brasileiros.

Basta mencionar, como ilustração, que a comparação entre os 15 municípios brasileiros com mais de 1 milhão de habitantes evidencia que as receitas municipais por habitante variaram em 2011 entre o máximo de R\$2.923,00 para Porto Alegre e valor quase quatro vezes menor ( $\mathrm{R} \$ 761,00)$ para o município de São Gonçalo, no Rio de Janeiro considerados os dados da Secretaria do Tesouro Nacional. 
Tendo em vista esse quadro, para o Prêmio "Municípios que Fazem Render Mais" há um duplo desafio, sintetizado pelas seguintes questões:

v Como estabelecer parâmetros comparativos do que venha a ser "render mais" quando as realidades, os desafios e os recursos para enfrentá-los - que conformam, em ampla medida, a capacidade de governo - são tão díspares?

จ De que forma captar essas disparidades de forma a melhor subsidiar os processos de escolha nas sucessivas etapas do processo de premiação?

Nesse sentido, a capacidade de governo é permeada por determinações, limites e oportunidades que estão, em ampla medida, relacionados a fatores de natureza econômica, social e político-administrativa, a respeito dos quais há ampla gama de informações estatísticas de que se pode lançar mão para comparar distintas realidades e, mais importante, a respeito dos quais parece haver menor nível de divergência entre as diferentes correntes de pensamento e campos de estudo. Parece razoavelmente estabelecido que, por exemplo, a maior ou menor disponibilidade de receitas municipais afeta a capacidade de governo. Assim, o desafio passa a ser a adequada escolha de indicadores ante o amplo espectro de dados e informações disponíveis.

Reitere-se o pressuposto básico de que a capacidade de governo é diretamente afetada por um conjunto de fatores que, ainda que parcialmente, podem ajudar a compreender os diferentes contextos nos quais os governos atuam. Para isso, foi selecionado um conjunto de variáveis que apresenta considerável potencial diagnóstico a respeito da realidade "herdada" por qualquer governo municipal ao iniciar seu mandato, de maneira a apresentar informações capazes de fornecer um panorama expressivo do marco situacional mais amplo a partir do qual a equipe de governo passa a escolher prioridades, tomar decisões e implementar ações.

É importante acrescentar, por fim, que a seleção das variáveis utilizadas na base de dados não foi orientada pela busca de evidências voltadas à percepção de melhorias (ou não) quanto ao desempenho ou aos resultados alcançados pelas administrações municipais em curso. Não é objetivo do Prêmio relacionar indicadores às ações desenvolvidas pelas atuais gestões municipais. O que interessa é enxergar se os indicadores relativos às áreas avaliadas são mais, ou menos, elevados comparativamente aos demais municípios.

Em síntese, a abordagem para a estruturação dessa base de dados foi orientada por dois aspectos fundamentais: 1) o reconhecimento das diferenças quanto às condições de realização de políticas públicas e programas dos governos municipais considerando-se três dimensões: econômica, social, e de gestão municipal e 2) a perspectiva comparada, com vistas a buscar os limites e os desafios próprios ao contexto de cada município diante dos demais.

Com base nessa abordagem, a montagem dos indicadores comparativos foi orientada pelos seguintes cuidados metodológicos quanto à seleção dos dados a serem utilizados: a) disponibilidade de informação para os 645 municípios do estado; b) disponibilidade de infor- 
mações primárias em fontes oficiais; c) periodicidade anual e maior atualidade possível das informações; d) em alguns casos, utilização de médias com base em anos recentes de forma a minimizar efeitos conjunturais em indicadores sujeitos a expressivas oscilações (exemplos: violência, mortalidade infantil, crescimento do emprego etc.); e) expressiva variabilidade na escala de valores observados com vistas a facilitar o contraste entre os municípios; f) montagem de indicadores expressos em taxas (ou valores per capita) e não em valores absolutos, com vistas a permitir melhor comparabilidade; g) "leitura imediata do indicador", ou seja, facilidade de sua compreensão sem necessidade de domínio de técnicas estatísticas mais complexas ou de consulta a outras fontes.

Esse processo resultou na seleção de 19 indicadores, dos quais seis relativos à dimensão econômica, nove relativos à dimensão social e quatro relativos à dimensão gestão municipal. Em seguida, procedeu-se à classificação de todos os municípios paulistas em um ranking estadual que os ordenou da melhor à pior posição em cada indicador considerado isoladamente - o pressuposto adotado é o de que o contexto no qual se encontra o governo é mais favorável quanto melhor o indicador, e vice-versa - , e posterior estratificação por quintis (compostos por 129 municípios cada), denominados "superior", "intermediário superior", "mediano", "intermediário inferior" e "inferior", facilitando assim a comparação entre os municípios.

Por fim, consideradas as posições de cada município nos rankings relativos a cada indicador, os indicadores foram agrupados conforme as três dimensões (econômica, social e de gestão municipal), constituindo-se assim um ranking geral em cada dimensão, atribuindo-se o mesmo aos indicadores que as compuseram. Também para esses rankings gerais os municípios foram divididos em quintis para facilitar a comparação.

É importante ressaltar que o objetivo de se estabelecer os rankings relativos às três dimensões não foi a criação de índices sintéticos sobre o contexto municipal, ainda que não esteja descartada essa possibilidade.

A tabela 1 apresenta um quadro sintético dos 19 indicadores selecionados segundo as dimensões (econômica, social e de gestão municipal) em que foram agrupados. De forma a evitar a acentuação desnecessária acerca da percepção das enormes desigualdades existentes e eventuais distorções dos dados referentes aos municípios situados nas posições extremas, os números apresentados nas tabelas são os referentes às medianas do $1^{\circ}$ quintil (65ํo entre 129 municípios com melhores posições em cada indicador), do $3^{\circ}$ quintil (correspondente, portanto, à mediana estadual) e do 5우 quintil (65ํㅡㄹ entre os 129 municípios nas últimas posições em cada indicador, ou $581^{\circ}$ no ranking estadual).

Como se pode observar na última coluna, as desigualdades são bastante acentuadas em todos os indicadores selecionados, com os valores entre as medianas do $1^{\mathrm{o}}$ e do $5^{\mathrm{o}}$ quintil variando entre mais de duas e quase sete vezes em 15 dos 19 indicadores em questão. Se fossem considerados, em cada indicador, os municípios melhor e pior situados no ranking estadual, em 13 dos 19 indicadores as variações superariam nada menos que 10 vezes. 
Tabela 1

\section{Quadro síntese dos indicadores municipais selecionados segundo os valores medianos do

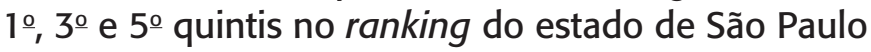

\begin{tabular}{|c|c|c|c|c|c|}
\hline \multicolumn{2}{|c|}{ Dimensões / indicadores selecionados } & 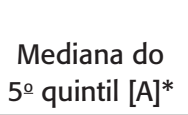 & $\begin{array}{c}\text { Mediana } \\
\text { estadual ou } \\
\text { do 3 quintil* }\end{array}$ & $\begin{array}{l}\text { Mediana do } \\
1 \text { o quintil }[\mathrm{B}]^{*}\end{array}$ & $\begin{array}{c}{[\mathrm{B}]} \\
/ \\
{[\mathrm{A}]}\end{array}$ \\
\hline \multirow{6}{*}{ 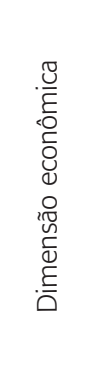 } & PIB per capita (em R\$) - 2008 & $7.623,56$ & $11.990,56$ & $25.171,39$ & 3,3 \\
\hline & Crescimento real do PIB entre 2004 e 2008 (\%) & $-9,31$ & 10,64 & 35,01 & $-4,76$ \\
\hline & Rendimento domiciliar per capita $(\mathrm{R} \$)-2010$ & 551,83 & 696,15 & 914,22 & 1,66 \\
\hline & Empregos / população em idade ativa (\%) - 2010 & 15,9 & 27,2 & 49,5 & 3,11 \\
\hline & $\begin{array}{l}\text { Taxa anual de expansão do emprego formal (\%) - } \\
2008 \text { a } 2010\end{array}$ & $-3,68$ & 4,19 & 11,29 & $-4,07$ \\
\hline & $\begin{array}{l}\text { Rendimento médio dos vínculos empregatícios } \\
(\mathrm{R} \$)-2010\end{array}$ & 949,77 & $1.189,21$ & $1.686,79$ & 1,78 \\
\hline \multirow{9}{*}{ 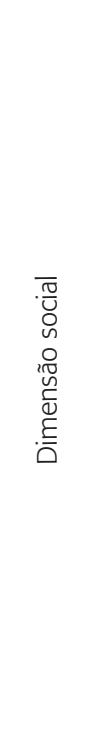 } & $\begin{array}{l}\text { Municipalização do ensino público fundamental } \\
(\%)-2010\end{array}$ & 32,7 & 54,0 & 100,0 & 3,06 \\
\hline & $\begin{array}{l}\text { Cobertura de educação infantil pela rede municipal } \\
(\%)-2010\end{array}$ & 28,8 & 42,0 & 60,3 & 2,09 \\
\hline & $\begin{array}{l}\text { Proxy da taxa de mortalidade infantil - média anual } \\
\text { do período 2007-09 }\end{array}$ & 22,0 & 12,6 & 3,3 & 0,15 \\
\hline & $\begin{array}{l}\text { Óbitos por causas externas por grupo de } 10 \text { mil } \\
\text { habitantes - média anual do período 2005-09 }\end{array}$ & 39,8 & 57,6 & 79,3 & 1,99 \\
\hline & $\begin{array}{l}\text { Servidores na saúde municipal por grupo de } 10 \text { mil } \\
\text { habitantes - } 2010\end{array}$ & 43,9 & 74,2 & 134,3 & 3,06 \\
\hline & $\begin{array}{l}\text { Taxa de pobreza (\% de domicílios com renda } \\
\text { mensal familiar per capita }<\text { R } \$ 140,00 \text { ) }-2010\end{array}$ & 13,3 & 6,7 & 3,8 & 0,29 \\
\hline & $\begin{array}{l}\text { Cobertura do Programa Bolsa Família / famílias } \\
\text { pobres (\%) - } 2011\end{array}$ & 58,8 & 97,8 & 119,2 & 2,03 \\
\hline & $\begin{array}{l}\text { Beneficiários do Benefício de Prestação Continuada } \\
\text { / famílias pobres (\%) - } 2011\end{array}$ & 32,1 & 68,3 & 125,5 & 3,91 \\
\hline & Município verde-azul (nota) & 19,72 & 56,99 & 85,22 & 4,32 \\
\hline \multirow{4}{*}{ 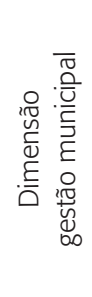 } & $\begin{array}{l}\text { Receita municipal per capita }(\mathrm{R} \$) \text { - média anual do } \\
\text { período 2008-10 }\end{array}$ & $1.419,08$ & $2.006,93$ & $3.668,02$ & 2,58 \\
\hline & Receita própria / receita total (\%) - 2010 & 6,6 & 17,1 & 36,5 & 5,53 \\
\hline & $\begin{array}{l}\text { Servidores municipais por grupo de mil habitantes } \\
-2009\end{array}$ & 23,0 & 37,3 & 71,9 & 3,13 \\
\hline & $\begin{array}{l}\text { Gastos sociais e em infraestrutura / total das } \\
\text { despesas municipais (\%) - } 2010\end{array}$ & 71,1 & 79,4 & 85,1 & 1,20 \\
\hline \multicolumn{6}{|c|}{$\begin{array}{l}\text { * Os valores representam os dos municípios situados nas } 581 \text { a (mediana do 5o quintil), 323a (mediana estadual) e 65a } \\
\text { (mediana do } 1 \text { o quintil) posições no ranking estadual de cada indicador. }\end{array}$} \\
\hline
\end{tabular}

Fonte: Prêmio "Municípios que Fazem Render Mais" - Estado de São Paulo, 2011. 
As variáveis que compõem a dimensão econômica são indicativas de que as desigualdades entre os municípios quanto à produção da riqueza, níveis de renda da população, dinamismo e inserção no mercado de força de trabalho influenciam expressivamente a capacidade de governo, pois ocasionam substanciais vantagens ou desvantagens comparativas tanto do ponto de vista da geração de receita municipal quanto da maior ou menor demanda por serviços públicos e programas sociais.

Na dimensão social, as variáveis selecionadas também expressam índices mais ou menos favoráveis para a capacidade de governo, dada sua estreita associação com algumas das principais competências a cargo dos municípios no federalismo brasileiro. Como se pode verificar na tabela 1 , o conjunto de indicadores selecionados é, por um lado, bastante sensível à ação municipal, ou seja, tende a variar positiva ou negativamente, em ritmos diferenciados, conforme a atuação do poder público municipal seja mais ou menos efetiva. Por outro lado, configuram um quadro geral com elevado potencial de influenciar a agenda pública e as escolhas de prioridades.

Como exemplo, pode-se citar a taxa de óbitos por causas externas por grupo de 10 mil habitantes. Como se sabe, a grande maioria desses óbitos é provocada por homicídios e acidentes automobilísticos. No caso destes, cabe aos municípios atuarem em questões relacionadas à sinalização, ao sistema viário e à educação no trânsito. E, no caso dos homicídios, muito embora segurança pública seja atribuição estadual quanto ao policiamento, é sabido que cada vez mais os municípios são "pressionados" pelos eleitores a "fazerem sua parte", tais como melhorar a iluminação e instalar câmeras de vigilância, implantar, estruturar e equipar guardas municipais e mesmo prover suportes (edificações, por exemplo) como contrapartida para a obtenção, junto ao governo estadual, de efetivos policiais operando nos municípios. O próprio governo federal, por meio de diversos programas, tem apoiado diretamente os municípios no quesito segurança pública.

Além disso, essas variáveis são também indicativas de mudanças nas pautas das políticas públicas. Se, por exemplo, a cobertura da educação infantil é baixa, o que parece mais desejável ou urgente — do ponto de vista do interesse público ou do cálculo quanto ao retorno eleitoral - é a expansão de vagas, mas se a cobertura já é mais elevada, na medida em que declina a demanda reprimida, a tendência é que a pauta seja progressivamente deslocada para questões relacionadas à qualidade do atendimento. Raciocínios similares podem ser aplicados aos demais indicadores selecionados que compõem a dimensão social.

Quanto à dimensão gestão municipal, as variáveis selecionadas são ainda mais diretamente associadas à capacidade de governo. Elas apresentam elevada capacidade preditiva sobre "a margem de manobra" mais ampla ou mais estreita com a qual contam os governos municipais para atuar.

O potencial de fomentar realizações e as estratégias preferenciais a serem adotadas dependem estreitamente da receita municipal, da capacidade própria de arrecadação, do 
tamanho das máquinas municipais (é importante lembrar que há pouca margem para ganhos de produtividade sem perda de qualidade em áreas intensivas em mão de obra, como educação e saúde) e da maior ou menor proporção dos gastos nas áreas sociais e de infraestrutura.

No caso desse último indicador, relativo à proporção dos gastos nas áreas sociais e de infraestrutura, o pressuposto é o de que, quanto maior a proporção das despesas no conjunto dessas áreas, melhor tende a ser a alocação dos recursos orçamentários - e, portanto, maior a capacidade de governo - , uma vez que será percentualmente menor o montante de recursos alocados para os dispêndios nas áreas-meio. Para o cálculo deste indicador foram analisados os balanços orçamentários da perspectiva da classificação funcional, considerando-se sociais e de infraestrutura as despesas assinaladas nas seguintes funções: segurança pública, assistência social, saúde, trabalho, educação, cultura, direitos da cidadania, urbanismo, habitação, saneamento, gestão ambiental, agricultura, organização agrária, indústria, comércio e serviços, energia, transporte e desporto e lazer.

Ao mesmo tempo, as variáveis relativas à dimensão gestão municipal são as que dependem mais diretamente das decisões e estratégias adotadas pelo poder público municipal, podendo resultar em rápida expansão ou obstáculo à capacidade de governo no curto espaço de um único mandato. Nesse sentido, as variáveis de gestão municipal são de perfil predominantemente endógeno (ou seja, menos expostas a fatores incontroláveis), pois estão mais estreitamente associadas ao que fazem ou deixam de fazer os governos a partir da disponibilidade de recursos com que contam e das condições concretas de funcionamento do aparato municipal.

Em síntese, consideradas conjuntamente as dimensões econômica, social e de gestão municipal, pode-se inferir que a capacidade de governo seja composta por um sistema interativo de fatores que tende a apresentar tendência de expansão dessa capacidade na medida em que sejam melhores os indicadores considerados. Nesse molde interpretativo, o contrário também é verdadeiro, ou seja, se as variáveis relacionadas às várias dimensões são menos vantajosas, a capacidade de governo tende a ser menor. Tanto faz, para isso, se pensarmos a evolução da capacidade de governo ao longo do tempo para um mesmo ente governamental (por exemplo, comparando duas gestões em um mesmo município), ou se comparamos entes governamentais entre si em um dado momento específico (por exemplo, dois ou mais municípios em um mesmo período de tempo, como foi nosso interesse especificamente para o Prêmio).

A figura 1 representa, em perspectiva tridimensional, dois municípios hipotéticos. $\mathrm{O}$ município "B" é ilustrativo de um caso de "elevada capacidade de governo", já que, comparativamente a "A", representa um contexto de vantagens nas três dimensões (econômica, social e de gestão municipal), que, por sua vez, caracterizaria assim um caso de "baixa capacidade de governar". É entre essas posições extremas, nas quais ocorrem vantagens (e desvantagens) simultaneamente nas três dimensões, que se pode encontrar o mundo real das administrações municipais. 
Figura 1

A função capacidade de governar

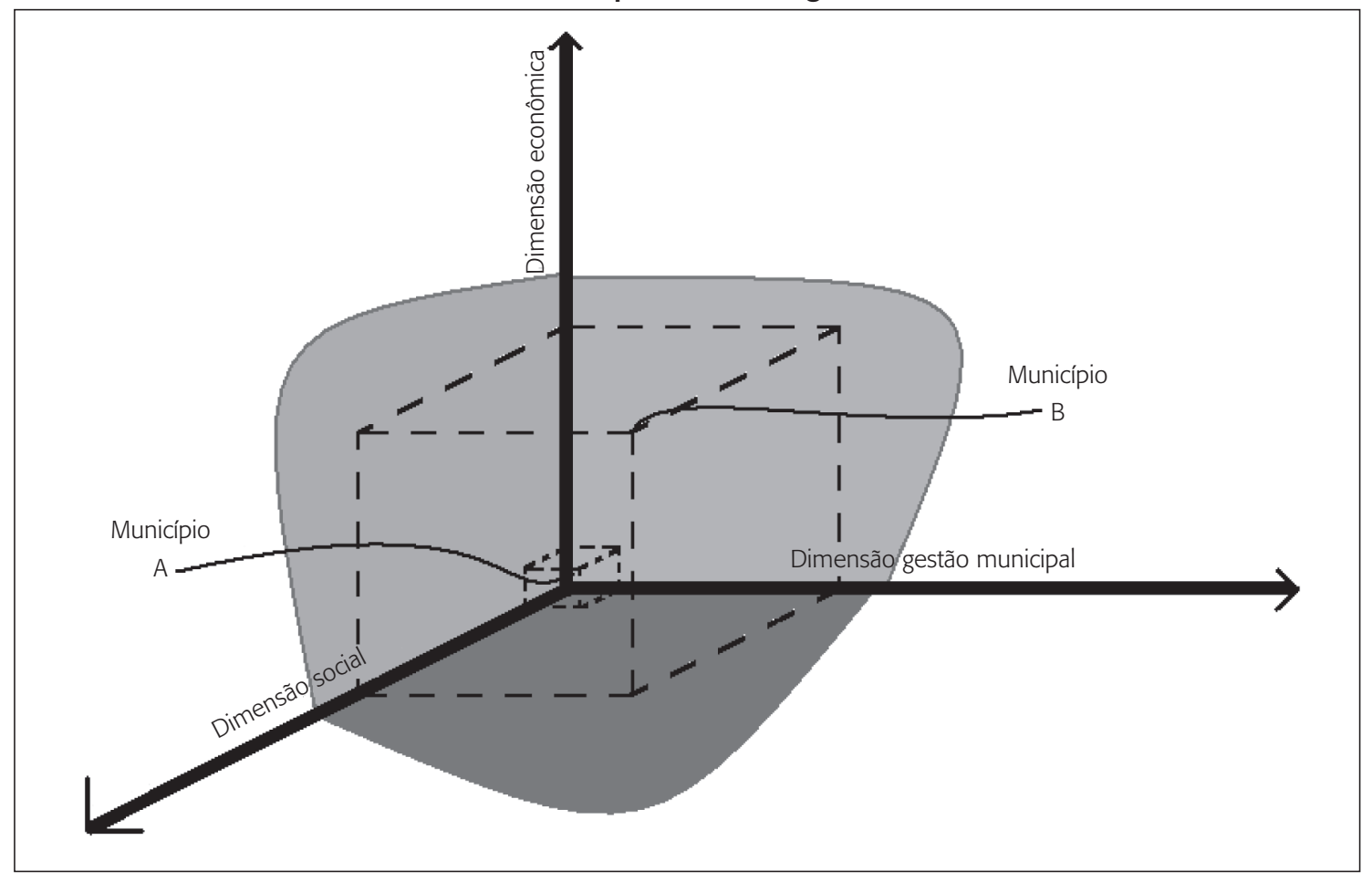

Fonte: Elaborado pelos autores.

\section{Algumas comparações entre os municípios paulistas}

De uma forma geral, são menos frequentes os casos nos quais os municípios apresentem acentuadas vantagens (ou acentuadas desvantagens) de forma simultânea nas três dimensões, como respectivamente ilustram os casos "B" e "A" da figura 1. Ao classificar os 645 municípios paulistas, conforme estejam situados abaixo ou acima das posições medianas estaduais em cada dimensão, obtém-se uma distribuição na qual há 117 casos $(18,1 \%)$ que apresentam posição acima da mediana nas três dimensões que agrupam os indicadores selecionados (econômico, social e gestão municipal). No outro extremo — ou seja, na posição abaixo das medianas nas três dimensões - têm-se 121 casos $(18,8 \%)$. Em posições intermediárias, há 407 municípios, dos quais 210 (32,6\%) casos nos quais ocorrem combinações com posições acima das medianas em duas dimensões, e abaixo em outra, e outros 197 (30,6\%) em situação inversa (posição abaixo das medianas nas duas dimensões e acima em outra). A tabela 2 mostra a distribuição dos municípios por porte populacional conforme essa forma de classificação. 
Tabela 2

Distribuição dos municípios paulistas por porte populacional segundo as posições em relação às medianas estaduais nas dimensões econômica, de gestão municipal e social

\begin{tabular}{|c|c|c|c|c|c|c|c|c|c|c|c|c|}
\hline \multirow{4}{*}{ 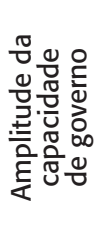 } & \multirow{4}{*}{$\begin{array}{l}\text { Convergência ou } \\
\text { divergência entre } \\
\text { as dimensões }\end{array}$} & \multirow{2}{*}{\multicolumn{3}{|c|}{$\begin{array}{l}\text { Posição do município em } \\
\text { relação à mediana estadual por } \\
\text { dimensão }\end{array}$}} & \multicolumn{8}{|c|}{ Distribuição dos municípios por porte populacional } \\
\hline & & & & & \multicolumn{2}{|c|}{ Total } & \multicolumn{2}{|c|}{ até 50 mil } & \multicolumn{2}{|c|}{$\begin{array}{c}\text { + de } 50 \mathrm{mil} \\
\text { a } 250 \mathrm{mil}\end{array}$} & \multicolumn{2}{|c|}{$\begin{array}{c}\text { + de } 250 \\
\text { mil }\end{array}$} \\
\hline & & \multirow{2}{*}{ econômica } & \multirow{2}{*}{$\begin{array}{l}\text { gestão } \\
\text { municipal }\end{array}$} & \multirow{2}{*}{ social } & n.a. & $\%$ & n.a. & $\%$ & n.a. & $\%$ & n.a. & $\%$ \\
\hline & & & & & 645 & 100,0 & 521 & 80,8 & 98 & 15,2 & 26 & 4,0 \\
\hline \multirow{4}{*}{ 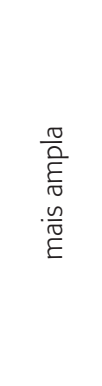 } & $\begin{array}{l}\text { Convergência nas } \\
\text { três dimensões }\end{array}$ & acima & acima & acima & 117 & 100,0 & 96 & 82,1 & 19 & 16,2 & 2 & 1,7 \\
\hline & $\begin{array}{l}\text { Divergência na } \\
\text { dimensão social }\end{array}$ & acima & acima & abaixo & 64 & 100,0 & 39 & 60,9 & 19 & 29,7 & 6 & 9,4 \\
\hline & $\begin{array}{l}\text { Divergência na } \\
\text { dimensão gestão } \\
\text { municipal }\end{array}$ & acima & abaixo & acima & 56 & 100,0 & 40 & 71,4 & 14 & 25,0 & 2 & 3,6 \\
\hline & $\begin{array}{l}\text { Divergência } \\
\text { na dimensão } \\
\text { econômica }\end{array}$ & abaixo & acima & acima & 90 & 100,0 & 88 & 97,8 & 2 & 2,2 & 0 & 0,0 \\
\hline \multirow{4}{*}{ 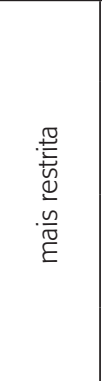 } & $\begin{array}{l}\text { Divergência na } \\
\text { dimensão social }\end{array}$ & abaixo & abaixo & acima & 60 & 100,0 & 60 & 100,0 & 0 & 0,0 & 0 & 0,0 \\
\hline & $\begin{array}{c}\text { Divergência na } \\
\text { dimensão gestão } \\
\text { municipal }\end{array}$ & abaixo & acima & abaixo & 52 & 100,0 & 49 & 94,2 & 2 & 3,8 & 1 & 1,9 \\
\hline & $\begin{array}{l}\text { Divergência } \\
\text { na dimensão } \\
\text { econômica }\end{array}$ & acima & abaixo & abaixo & 85 & 100,0 & 39 & 45,9 & 34 & 40,0 & 12 & 14,1 \\
\hline & $\begin{array}{l}\text { Convergência nas } \\
\text { três dimensões }\end{array}$ & abaixo & abaixo & abaixo & 121 & 100,0 & 110 & 90,9 & 8 & 6,6 & 3 & 2,5 \\
\hline
\end{tabular}

Fonte: Prêmio "Municípios que Fazem Render Mais" - Estado de São Paulo, 2011.

Os dados revelam que, entre os 26 municípios mais populosos (acima de 250 mil habitantes), a grande maioria apresenta vantagem comparativa quanto à dimensão econômica, com 22 casos nos quais as posições no ranking estadual estão acima da mediana. Entretanto, há apenas 10 casos nos quais a capacidade de governo seria "mais ampla" de acordo com o critério adotado na tabela 2. Entre esses, há dois casos com posição acima da mediana estadual simultaneamente nas três dimensões, e oito com posições acima da mediana em duas dimensões e abaixo da mediana em uma dimensão.

Ainda entre os 26 municípios mais populosos, em posição comparativamente menos vantajosa, nos quais a capacidade de governo seria mais restrita, têm-se 16 casos. Destes, 13 municípios ocupam posições abaixo das medianas estaduais em duas dimensões, e os outros 3 estão abaixo das medianas simultaneamente nas três dimensões analisadas.

No caso dos 98 municípios de porte médio (entre 50 mil e 250 mil habitantes), o perfil distributivo é bastante similar ao dos grandes municípios no que tange à dimensão econômica, 
com a maioria (86 casos) ocupando posição comparativamente mais vantajosa, ou seja, acima da mediana estadual.

Mas, diferentemente do que ocorre entre os municípios mais populosos, há maior concentração dos municípios "médios" entre aqueles que apresentam posição acima da mediana simultaneamente nas três dimensões (19 casos), ou em pelo menos duas delas (35 casos), totalizando 54 casos. Com capacidade de governo mais restrita estão os demais 44 municípios, dos quais 36 estão em posição abaixo da mediana estadual em duas das dimensões analisadas, e os outros oito municípios simultaneamente nas três dimensões.

No caso dos 521 municípios menos populosos (até 50 mil habitantes), ocorre o inverso quanto à dimensão econômica, uma vez que a maioria (307 casos) está abaixo da mediana estadual. Mas, entre eles, chama a atenção a ocorrência de 88 casos nos quais a capacidade de governo seria mais ampla, pois estão acima das medianas estaduais simultaneamente nas dimensões social e de gestão municipal e ao mesmo tempo abaixo da mediana na dimensão econômica.

Além disso, é entre os municípios menos populosos que ocorrem todos os 60 casos que combinam posições abaixo das medianas estaduais nas dimensões econômica e de gestão municipal e, ao mesmo tempo, acima da mediana estadual na dimensão social.

Já nas duas posições extremas estão quase 40\% dos 521 municípios menos populosos, sendo 96 casos com a mais ampla capacidade de governo (posições acima das medianas nas três dimensões) e 110 com a mais restrita (posições abaixo das medianas nas três dimensões).

Considerando ainda o critério de porte populacional, há diferenças expressivas no conjunto dos municípios paulistas também quando comparados da perspectiva dos indicadores ou variáveis que compõem cada dimensão.

A tabela 3 apresenta, segundo o porte populacional, o quantitativo dos municípios situados nos dois primeiros quintis ("superior" e "intermediário superior") de cada indicador e dimensão. Em uma hipotética distribuição perfeita, 40\% dos municípios deveriam estar nessas posições em cada um dos indicadores.

Tabela 3

Municípios situados nos quintis superior e intermediário superior por dimensão e indicadores selecionados segundo o porte populacional

\begin{tabular}{|c|c|c|c|c|c|c|}
\hline \multirow{3}{*}{ Dimensões e Indicadores } & \multicolumn{6}{|c|}{ Porte populacional } \\
\hline & \multicolumn{2}{|c|}{ até $50 \mathrm{mil}$} & \multicolumn{2}{|c|}{$\begin{array}{c}\text { + de } 50 \text { mil a } 250 \\
\text { mil }\end{array}$} & \multicolumn{2}{|c|}{ + de $250 \mathrm{mil}$} \\
\hline & n.a. & $(\%)$ & n.a. & $(\%)$ & n.a. & $(\%)$ \\
\hline Total de Municípios & 521 & $(100,0)$ & 98 & $(100,0)$ & 26 & $(100,0)$ \\
\hline Dimensão Econômica & 151 & $(29,0)$ & 83 & $(84,7)$ & 24 & $(92,3)$ \\
\hline PIB per capita $(\mathrm{em} \mathrm{R} \$)-2008$ & 171 & $(32,8)$ & 67 & $(68,4)$ & 20 & $(76,9)$ \\
\hline crescimento real do PIB entre 2004 e 2008 (\%) & 192 & $(36,9)$ & 46 & $(46,9)$ & 20 & $(76,9)$ \\
\hline rendimento domiciliar per capita $(\mathrm{R} \$)-2010$ & 155 & $(29,8)$ & 82 & $(83,7)$ & 21 & $(80,8)$ \\
\hline
\end{tabular}




\begin{tabular}{|c|c|c|c|c|c|c|}
\hline \multirow{3}{*}{ Dimensões e Indicadores } & \multicolumn{6}{|c|}{ Porte populacional } \\
\hline & \multicolumn{2}{|c|}{ até 50 mil } & \multicolumn{2}{|c|}{$\begin{array}{c}\text { + de } 50 \text { mil a } 250 \\
\text { mil }\end{array}$} & \multicolumn{2}{|c|}{+ de $250 \mathrm{mil}$} \\
\hline & n.a. & $(\%)$ & n.a. & (\%) & n.a. & $(\%)$ \\
\hline empregos / população em idade ativa (\%) - 2010 & 170 & $(32,6)$ & 69 & $(70,4)$ & 19 & $(73,1)$ \\
\hline $\begin{array}{l}\text { taxa anual de expansão do emprego formal (\%)- } \\
2008 \text { a } 2010\end{array}$ & 185 & $(35,5)$ & 56 & $(57,1)$ & 17 & $(65,4)$ \\
\hline $\begin{array}{l}\text { rendimento médio dos vínculos empregatícios ( } R \$ \text { ) } \\
-2010\end{array}$ & 155 & $(29,8)$ & 79 & $(80,6)$ & 24 & $(92,3)$ \\
\hline Dimensão Social & 229 & $(44,0)$ & 26 & $(26,5)$ & 3 & $(11,5)$ \\
\hline $\begin{array}{l}\text { municipalização do ensino público fundamental } \\
(\%)-2010\end{array}$ & 221 & $(42,4)$ & 34 & $(34,7)$ & 4 & $(15,4)$ \\
\hline $\begin{array}{l}\text { cobertura de educação infantil pela rede municipal } \\
(\%)-2010\end{array}$ & 220 & $(42,2)$ & 35 & $(35,7)$ & 3 & $(11,5)$ \\
\hline $\begin{array}{l}\text { proxy da taxa de mortalidade infantil - média anual } \\
\text { do período 2007-09 }\end{array}$ & 221 & $(42,4)$ & 31 & $(31,6)$ & 6 & $(23,1)$ \\
\hline $\begin{array}{l}\text { óbitos por causas externas por grupo de } 10 \text { mil habi- } \\
\text { tantes - média anual do período } 2005-09\end{array}$ & 220 & $(42,2)$ & 33 & $(33,7)$ & 5 & $(19,2)$ \\
\hline $\begin{array}{l}\text { servidores na saúde municipal por grupo de } 10 \text { mil } \\
\text { habitantes - } 2010\end{array}$ & 243 & $(46,6)$ & 12 & $(12,2)$ & 5 & $(19,2)$ \\
\hline $\begin{array}{l}\text { Taxa de pobreza (\% de domicílios com renda mensal } \\
\text { familiar per capita }<R \$ 140,00)-2010\end{array}$ & 204 & $(39,2)$ & 44 & $(44,9)$ & 10 & $(38,5)$ \\
\hline $\begin{array}{l}\text { cobertura do Programa Bolsa Família / famílias pobres } \\
(\%)-2011\end{array}$ & 227 & $(43,6)$ & 26 & $(26,5)$ & 6 & $(23,1)$ \\
\hline $\begin{array}{l}\text { beneficiários do Benefício de Prestação Continuada / } \\
\text { famílias pobres (\%)- } 2011\end{array}$ & 222 & $(42,6)$ & 35 & $(35,7)$ & 3 & $(11,5)$ \\
\hline município verde-azul (nota) & 203 & $(39,0)$ & 43 & $(43,9)$ & 12 & $(46,2)$ \\
\hline Dimensão Gestão Municipal & 223 & $(42,8)$ & 31 & $(31,6)$ & 5 & $(19,2)$ \\
\hline $\begin{array}{l}\text { receita municipal per capita }(\mathrm{R} \$) \text { - média anual do } \\
\text { período 2008-10 }\end{array}$ & 231 & $(44,3)$ & 19 & $(19,4)$ & 8 & $(30,8)$ \\
\hline receita própria / receita total (\%)- 2010 & 138 & $(26,5)$ & 93 & $(94,9)$ & 26 & $(100,0)$ \\
\hline $\begin{array}{l}\text { servidores municipais por grupo de mil habitantes } \\
-2009\end{array}$ & 251 & $(48,2)$ & 6 & $(6,1)$ & 0 & $(0,0)$ \\
\hline $\begin{array}{l}\text { gastos sociais e em infraestrutura / total das despesas } \\
\text { municipais (\%)- } 2010\end{array}$ & 219 & $(42,0)$ & 31 & $(31,6)$ & 7 & $(26,9)$ \\
\hline
\end{tabular}

Fonte: Prêmio "Municípios que Fazem Render Mais" - Estado de São Paulo, 2011.

Chama a atenção que os indicadores agrupados em cada uma das três dimensões apresentam forte convergência entre si quando analisados da perspectiva do porte populacional dos municípios. Igualmente, que os resultados parecem bastante coerentes com o que se poderia esperar a respeito, quando comparadas as três dimensões. 
Assim, quando considerada a dimensão econômica, a capacidade de governo parece marcadamente vantajosa para os municípios "médios" (entre 50 mil e 250 mil habitantes) e ainda mais para os "grandes" (mais de 250 mil habitantes), comparativamente aos "pequenos" (até 50 mil habitantes). Dos 26 municípios com mais de 250 mil habitantes, nada menos que 24 estão situados nos dois quintis superiores na dimensão econômica, o mesmo ocorrendo em 83 dos 98 municípios "médios", enquanto entre os com até 50 mil habitantes estão situados nestes mesmos dois quintis superiores "apenas" 151 (29,0\%) dos 521 municípios paulistas.

Se analisadas isoladamente cada uma das seis variáveis que compõem a dimensão econômica, a proporção de municípios "médios" e "grandes" considerados conjuntamente nos dois quintis superiores é mais que duas vezes superior à verificada para municípios "pequenos" em quatro delas (PIB per capita, rendimento domiciliar per capita, rendimento médio dos vínculos empregatícios e empregos formais como proporção da população em idade ativa). Os outros dois indicadores que compõem a dimensão econômica - crescimento do PIB e taxa anual de expansão do emprego - apresentam a mesma tendência claramente vantajosa para os municípios "grandes" e "médios", comparativamente aos pequenos.

Assim, como seria de se esperar, parece inequívoco que a capacidade de governo é comparativamente bastante favorecida pela dimensão econômica nos municípios grandes e médios comparativamente aos menos populosos (com até 50 mil habitantes).

Cabe sublinhar que há 33 municípios (11 pequenos, 15 médios e 7 grandes) que estão situados nos dois quintis superiores em todos os indicadores que compõem a dimensão econômica. No outro extremo (posição nos dois quintis inferiores em todos os indicadores da dimensão econômica) há 19 casos, todos com menos de 30 mil habitantes, dos quais 16 com menos de 10 mil habitantes.

Quanto à dimensão social, observa-se também expressiva convergência entre quase todos os indicadores selecionados. Mas, inversamente ao que ocorre na dimensão econômica, em sete dos nove indicadores sociais selecionados é evidente um padrão distributivo no qual os municípios menos populosos são mais frequentes nos dois quintis superiores (44\%) comparativamente aos municípios de porte médio (26,5\%) e principalmente aos mais populosos $(11,5 \%)$.

Dos 26 municípios paulistas "grandes", na maior parte das variáveis consideradas na dimensão social apenas alguns poucos estão situados nos dois quintis, sendo apenas três casos quanto à cobertura de educação infantil pela rede municipal, três quanto à cobertura pelo Benefício de Prestação Continuada, quatro quanto à municipalização do ensino público fundamental, cinco quanto à incidência de óbitos por causas externas, cinco quanto à proporção de servidores na saúde municipal e seis quanto à mortalidade infantil.

A mesma tendência de sub-representação, ainda que menos acentuada, se verifica entre os municípios "médios" no que diz respeito a estes mesmos indicadores, ocorrendo o oposto com os municípios "menores", entre os quais mais de $40 \%$ estão situados nos dois quintis superiores em todos os sete indicadores sociais mencionados.

Ou seja, os municípios menos populosos são os que tendem a apresentar, quanto aos indicadores sociais aqui considerados, melhor situação comparativamente aos "médios" e 
"grandes". As exceções a este padrão dizem respeito apenas à taxa de pobreza e ao indicador adotado para a temática ambiental (Município Verde-Azul). Nesses dois indicadores, o que se observa é uma distribuição mais homogênea, estando situados nos dois quintis superiores algo em torno de 39\% a 45\% do conjunto dos municípios, com frequência ligeiramente superior dos municípios mais populosos comparativamente aos de menor porte populacional.

Também na dimensão gestão municipal os municípios menos populosos são os que apresentam, quanto ao resultado geral dos quatro indicadores utilizados, vantagem comparativa em relação aos "médios", e estes em relação aos "grandes". Mas, diferentemente do que predomina entre os indicadores econômicos e entre os indicadores sociais, a análise de cada um dos indicadores de gestão municipal evidencia diferenças substanciais quanto à distribuição dos municípios conforme o porte populacional.

Refletindo sobre o potencial econômico, a variável relativa à proporção das receitas próprias sobre a receita total coloca em posição comparativamente vantajosa quanto à capacidade de governo os municípios "grandes" e "médios", quase todos situados nos dois quintis superiores no ranking estadual.

Mas a menor capacidade de os municípios "pequenos" gerarem receitas próprias é contrabalançada pelos mecanismos redistributivos da estrutura fiscal brasileira, por meio principalmente das transferências intergovernamentais vinculadas que, proporcionalmente, os beneficiam mais. Isso resulta que a receita municipal (próprias + transferências) seja, em termos per capita, mais elevada em grande parte dos municípios menos populosos comparativamente aos "médios" e "grandes", de forma que, entre os primeiros, 44,3\% estão nos dois quintis superiores do estado quanto a esse indicador, o mesmo ocorrendo com apenas 19,4\% dos municípios "médios" e 30,8\% dos "grandes".

No que diz respeito ao indicador relativo ao quadro de pessoal ("servidores municipais por grupo de mil habitantes"), a hipótese é a de que uma estrutura quantitativamente mais robusta colocaria os municípios, em princípio, em posição mais vantajosa para a prestação de serviços sob sua responsabilidade. Os dados evidenciam que as condições observadas nos municípios "pequenos" são comparativamente mais vantajosas com 48,2\% deles situados nos dois quintis superiores, proporção expressivamente mais elevada que a verificada entre os municípios "médios" (6,1\%) e os "grandes" (nenhum caso).

A mesma tendência se verifica em relação ao indicador relativo às despesas municipais ("gastos sociais e em infraestrutura/total das despesas municipais"): $42 \%$ dos pequenos estão nos dois quintis superiores, sendo 31,6\% dos "médios" e apenas 26,9\% dos grandes. Neste caso, a hipótese subjacente é que a capacidade de governo tende a ser mais ampla quanto maior for esta proporção, indicando situação mais favorável para que os municípios cumpram adequadamente suas competências, pois apresentam menor consumo de recursos com as funções-meio.

Se a perspectiva comparativa entre os municípios paulistas for a regional, também encontramos diferenças muito significativas quando se agrupam os conjuntos segundo as 15 regiões administrativas do estado. Ao classificar os municípios em cada uma das três dimensões, em duas categoriais - conforme estejam abaixo ou acima da mediana estadual —, encon- 
tram-se regiões que apresentam padrões opostos. A tabela 4 apresenta os dados a respeito, e nela as regiões estão ordenadas a partir das que apresentam as maiores proporções de municípios situados acima da mediana estadual na dimensão social.

Tabela 4

Quantidade e percentual de municípios paulistas acima das medianas estaduais nas dimensões econômica, gestão municipal e social, segundo as regiões administrativas

\begin{tabular}{|c|c|c|c|c|c|c|c|}
\hline \multirow[b]{2}{*}{ Regiões administrativas } & \multirow[b]{2}{*}{ Total } & \multicolumn{2}{|c|}{ Dimensão Econômica } & \multicolumn{2}{|c|}{$\begin{array}{c}\text { Dimensão } \\
\text { Gestão Municipal }\end{array}$} & \multicolumn{2}{|c|}{$\begin{array}{l}\text { Dimensão } \\
\text { Social }\end{array}$} \\
\hline & & n.a. & $\%$ & n.a. & $\%$ & n.a. & $\%$ \\
\hline Total & 645 & 324 & 50,2 & 323 & 50,1 & 323 & 50,1 \\
\hline Barretos & 19 & 9 & 47,4 & 13 & 68,4 & 19 & 100,0 \\
\hline São José do Rio Preto & 96 & 52 & 54,2 & 56 & 58,3 & 80 & 83,3 \\
\hline Araçatuba & 43 & 18 & 41,9 & 24 & 55,8 & 33 & 76,7 \\
\hline Ribeirão Preto & 25 & 17 & 68,0 & 13 & 52,0 & 19 & 76,0 \\
\hline Franca & 23 & 10 & 43,5 & 16 & 69,6 & 17 & 73,9 \\
\hline Presidente Prudente & 53 & 15 & 28,3 & 23 & 43,4 & 33 & 62,3 \\
\hline Marília & 51 & 18 & 35,3 & 25 & 49,0 & 28 & 54,9 \\
\hline Central & 26 & 12 & 46,2 & 12 & 46,2 & 14 & 53,8 \\
\hline Campinas & 90 & 68 & 75,6 & 47 & 52,2 & 36 & 40,0 \\
\hline Bauru & 39 & 17 & 43,6 & 13 & 33,3 & 14 & 35,9 \\
\hline Sorocaba & 79 & 32 & 40,5 & 32 & 40,5 & 18 & 22,8 \\
\hline São José dos Campos & 39 & 18 & 46,2 & 24 & 61,5 & 8 & 20,5 \\
\hline Santos & 9 & 8 & 88,9 & 7 & 77,8 & 1 & 11,1 \\
\hline Registro & 14 & 3 & 21,4 & 5 & 35,7 & 1 & 7,1 \\
\hline Metropolitana de São Paulo & 39 & 27 & 69,2 & 13 & 33,3 & 2 & 5,1 \\
\hline
\end{tabular}

Fonte: Prêmio "Municípios que Fazem Render Mais" - Estado de São Paulo, 2011.

Para uma primeira aproximação, podemos dividir o estado em três grupos de regiões.

O primeiro grupo representa as regiões de Barretos, São José do Rio Preto, Araçatuba, Ribeirão Preto, Franca e Presidente Prudente, totalizando 259 municípios, dos quais 201 $(77,6 \%)$ estão situados acima da mediana estadual na dimensão social. Na dimensão gestão municipal a situação também é comparativamente favorável para a maioria desses municípios, entre os quais 145 (56\%) estão acima da mediana estadual. Mas, quanto à dimensão econômica, menos da metade (121 casos ou 46,7\%) está acima da mediana estadual.

O segundo grupo engloba as regiões de Marília, Central e Campinas. Com 167 municípios, essas regiões apresentam situação intermediária tanto no que diz respeito à dimensão social - com as proporções de municípios situados acima da mediana estadual variando entre 40\% (Campinas) e 54,9\% (Marília) —, quanto na dimensão gestão municipal, estando acima 
da mediana estadual algo em torno de $50 \%$ dos municípios de cada região. Mas quanto à dimensão econômica os números são contrastantes. Na região de Campinas, 68 entre 90 municípios $(75,6 \%)$ estão acima da mediana estadual, mas as proporções são bem menores na região Central (12 dos 26 municípios ou 46,2\%) e de Marília, com apenas 18 dos 51 municípios (35,3\%) acima da mediana estadual.

As demais seis regiões do estado apresentam as menores proporções de municípios acima da mediana estadual na dimensão social - apenas 44 dos 219 municípios (20,1\%) nelas situados. Especificamente nas regiões de Santos, Registro e Metropolitana de São Paulo o quadro é mais grave, com apenas quatro de 62 municípios situados acima da mediana estadual na dimensão social.

Consideradas as três dimensões, a distribuição é mais convergente nas regiões de Bauru, Sorocaba e Registro, pois nelas há mais municípios abaixo do que acima das medianas estaduais tanto na dimensão social quanto na econômica e de gestão municipal.

Nas demais regiões os padrões distributivos são bastante divergentes. Na de São José dos Campos, com 39 municípios, apesar do menor potencial quando considerada a dimensão econômica, com 18 casos (46,2\%) acima da mediana estadual; na dimensão gestão municipal o quadro é mais favorável (24 municípios ou 61,5\% acima da mediana estadual), mas bastante desfavorável na dimensão social, com apenas oito (20,5\%) municípios acima da mediana estadual.

Entre os nove municípios da região de Santos, oito estão acima da mediana estadual na dimensão econômica e sete na dimensão gestão municipal, mas apenas um quando considerada a dimensão social.

Na Região Metropolitana de São Paulo a distribuição é também acentuadamente contraditória. Entre os 39 municípios que a compõem, a maioria (27 casos ou 69,2\%) está acima da mediana estadual na dimensão econômica, mas apenas 1/3 (13 casos) na dimensão gestão municipal, e uma ínfima minoria (três casos ou 6,3\%) quando considerada a dimensão social.

Esse padrão contraditório fica bastante evidente quando subdividimos os municípios em quintis. Há 14 casos situados simultaneamente em extremidades opostas, pois estão no quintil superior quando considerada a dimensão econômica e no quintil inferior quando considerada a dimensão social. Além da própria capital (São Paulo), esse grupo de municípios é composto por Guarulhos, Santo André, Osasco, Mogi das Cruzes, Diadema, Taboão da Serra, Cotia, Itapecerica da Serra, Cubatão, Jandira, Caieiras, Arujá e Vargem Grande Paulista, todos eles localizados na Região Metropolitana de São Paulo.

A figura 2 mostra quatro regiões com características diferenciadas quanto às posições dos municípios nos rankings das dimensões econômica e social do estado. O contraste é marcante entre a Região Metropolitana de São Paulo (potencial econômico elevado e indicadores sociais desfavoráveis) e Barretos, na qual os indicadores sociais são muito mais favoráveis em quase todos os municípios, independentemente de seu potencial econômico ser mais ou menos elevado. Por sua vez, na região de Registro predominam os municípios em posições desvantajosas em ambas as dimensões, e na região Administrativa Central do Estado os municípios se distribuem entre as mais variadas situações de vantagens e desvantagens tanto na dimensão econômica quanto na social. 
Figura 2

Dimensão econômica $x$ dimensão social. Estado de São Paulo regiões administrativas selecionadas

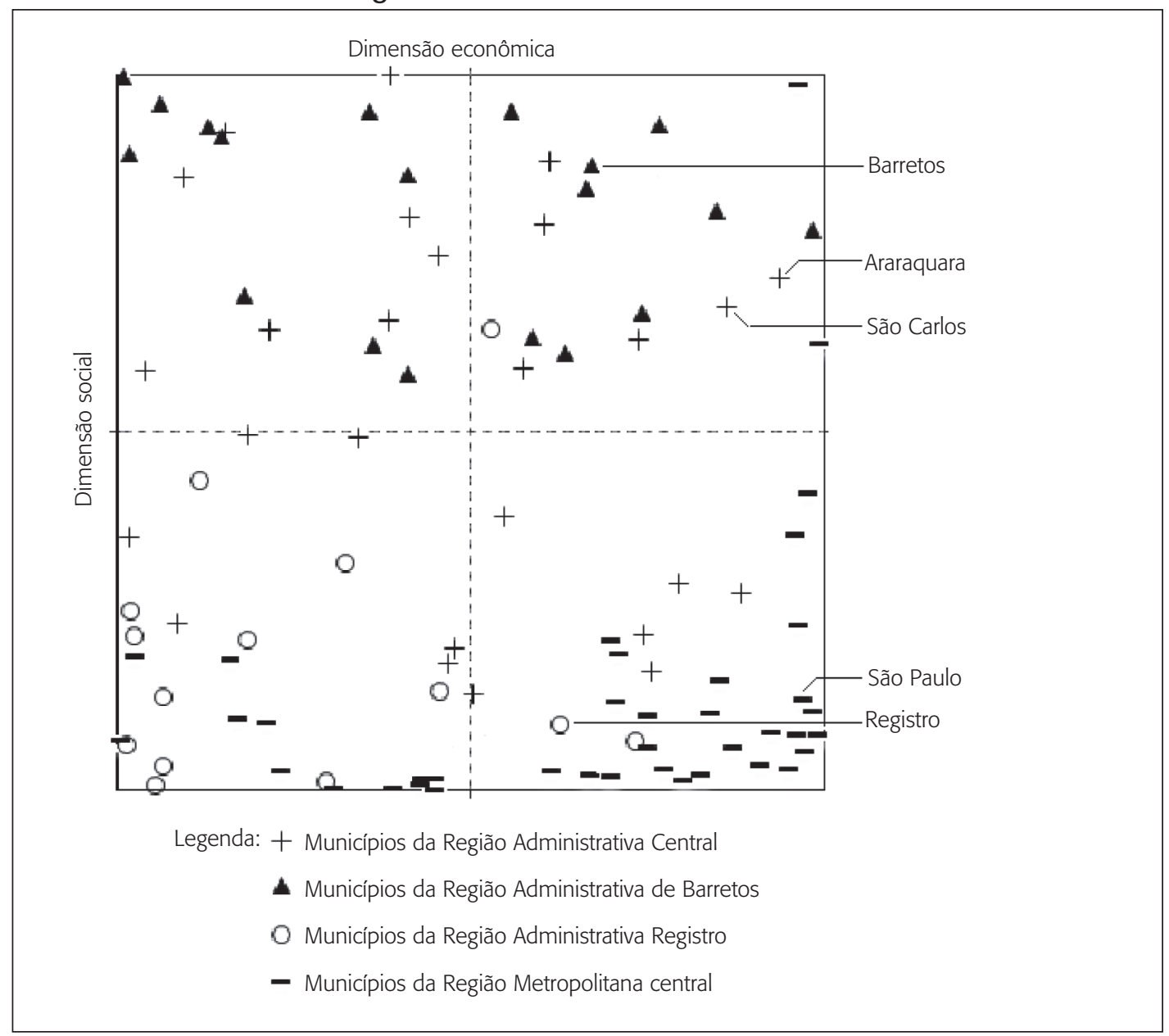

Fonte: Prêmio "Municípios que Fazem Render Mais" - Estado de São Paulo, 2011.

Em síntese, os dados revelados pelo conjunto de variáveis selecionadas são indicativos de que: i) há profundas desigualdades no conjunto dos municípios paulistas quanto à capacidade de governo no que dependem, nos termos aqui propostos, dos contextos econômico, social e de gestão municipal; ii) os municípios com mais de 50 mil habitantes apresentam nítida vantagem comparativamente aos menos populosos quanto à dimensão econômica; iii) essas vantagens não se traduzem em melhores indicadores sociais, uma vez que são os municípios "pequenos" que apresentam, em proporções mais elevadas, melhores posições no ranking estadual em relação a esses indicadores, ocorrendo o inverso (melhores indicadores na di- 
mensão econômica e piores na dimensão social) na maior parte dos municípios mais populosos; iv) quanto à dimensão gestão municipal, embora os dados devam ser interpretados com maior cautela e sejam insuficientes para análise mais assertiva, os indicadores selecionados também situam em posição mais vantajosa uma maior proporção de municípios "médios" e "pequenos" comparativamente aos mais populosos; v) na medida em que o conjunto dos indicadores selecionados possam ser considerados como expressivos ou reveladores da capacidade de governo, e apesar das acentuadas desigualdades, o balanço preliminar parece evidenciar contexto mais favorável aos governantes de grande parte dos municípios menos populosos, pois, mesmo em desvantagem da perspectiva dos indicadores econômicos, o poder público municipal conta com mais recursos humanos e fiscais, e os indicadores sociais são melhores em maior proporção nesses municípios comparativamente aos "médios" e "grandes"; vi) do ponto de vista regional, é possível identificar marcantes diferenças, com algumas regiões para as quais os dados evidenciam proporções comparativamente elevadas de municípios em posições vantajosas nas três dimensões; um segundo grupo, no qual as posições nos rankings, nas três dimensões, parecem convergentes; e um terceiro, no qual aparece clara a dissociação entre vantagens comparativas na dimensão econômica e desvantagens na dimensão social.

\section{Considerações finais}

O Prêmio "Municípios que Fazem Render Mais" sintetiza um conjunto de questões reflexivas e empíricas que procuram desvelar a realidade municipal brasileira em contextos diversos. Por meio de metodologia parcialmente proveniente do Prêmio "Gestão Pública e Cidadania", o Prêmio adotou outras metodologias, tais como questionários comuns e específicos e indicadores relacionados à realidade municipal.

Em relação às questões suscitadas pelo Prêmio, um primeiro aspecto refere-se ao impacto das desigualdades, tais como o desenvolvimento econômico, a renda per capita, o desempenho da gestão, as restrições fiscais, a cobertura de políticas sociais e a infraestrutura. Tudo isso torna a comparação entre municípios tarefa que exige escolhas de critérios que levem em conta os contextos (ou situações) de acordo com os quais os governos locais atuam, conforme vimos na seção sobre os indicadores utilizados.

Um segundo aspecto refere-se à seleção de indicadores qualitativos e quantitativos capazes de expressar comparações: a definição de três faixas populacionais; os voltados à competência municipal; e os que informassem sobre as condições de atuação dos prefeitos. Assim, a comparação entre municípios tornou-se mais equânime, pois os municípios analisados puderam ser observados em situação — verificada por meio de indicadores — mais assemelhada do ponto de vista comparativo, o que implicou, na segunda edição, a ampliação do papel dos indicadores e sua ponderação por meio de quintis. Note-se que o triângulo de governo torna-se mais visível quando os indicadores são trazidos à luz.

Um terceiro aspecto diz respeito aos desafios do trabalho de campo, em vários sentidos, o que implica, por exemplo, não ter — o Prêmio — uma visão oficialista, o que é possibilitado, 
metodologicamente, pela audição da oposição (institucional e/ou informal), pela análise de indicadores e pela independência dos membros dos Comitês de Avaliação.

Um quarto aspecto refere-se à expressão "render mais" que, embora pautada por balizas constitucionais, não implica "camisa de força" no tocante à expectativa de um modelo único de gestão. Foi possível verificar formas distintas de um município "fazer render mais", o que implicou olhar para a diversidade.

Um quinto aspecto refere-se à reflexão sobre o papel do construto teórico de Carlos Matus, utilizado como inspiração do Prêmio. A relação entre os três vértices do triângulo de governo - como vimos, o Projeto de governo, a Governabilidade e a Capacidade de Governo sintetiza os desafios da gestão pública. Tais desafios, qualificados conceitualmente por Matus, desdobram-se em situações concretas e demonstram que o método PES pode ser tomado como referência conceitual para a análise das gestões, sobretudo em perspectiva comparativa.

Tudo isso somado permite reflexões profundas acerca do ato de governar, para as quais este artigo pretendeu contribuir de forma preliminar. Outros artigos e pesquisas devem dar sequência a este esforço inicial.

Por fim, o Prêmio pretendeu, de maneira propositiva — daí o caráter voluntário das inscrições - valorizar a transparência dos recursos públicos, em sentido lato, tornando os exemplos municipais uma espécie de "banco de dados" para que outros municípios se inspirem a fazer reformas democratizantes e cidadãs. Mais ainda, a avaliação do critério transparência não se ateve à simples prestação de contas, representando, portanto, um passo em direção a um maior controle social e não apenas ao cumprimento de determinações legais.

\section{Referências}

CRUZ, Maria do C. M. T. et al. Gestão pública municipal no estado de São Paulo: elementos para um olhar analítico. In: VELOSO, João F. A et al. (Org.). Gestão municipal no Brasil: retrato das prefeituras. Brasília: Ipea, 2011.

DOWBOR, Ladislau; POCHMANN, Márcio (Org.). Políticas para o desenvolvimento local. São Paulo: Fundação Perseu Abramo, 2008.

MATUS, Carlos. O plano como aposta. In: GIACOMONI, James; PAGNUSSAT, José L. Planejamento e orçamento governamental: coletânea. Brasília: Enap, 2006. 2 v.

PRÊMIO Municípios que Fazem Render Mais — Estado de São Paulo. São Paulo: Centro de Estudos em Administração Pública e Governo da Fundação Getulio Vargas de São Paulo/Escola de Administração de Empresas de São Paulo. 2011. Disponível em: <www.fiesp.com.br/premio-municipios/>. Acesso em: 27 ago. 2012.

SANTOS, Anselmo L. dos; ARAÚJO, Fátima F. de (Org.). Construindo o diagnóstico municipal: uma metodologia - perguntas estratégicas sobre as principais áreas da administração que o gestor deve fazer. São Paulo: Fundação Prefeito Faria Lima (Cepam); Unicamp, 2008. 
SPINK, Peter; CACCIA BAVA, Silvio; PAULICS, Veronika (Org.). Novos contornos da gestão local: conceitos em construção. São Paulo: Pólis; Programa Gestão Pública e Cidadania/FGV/Eaesp, 2002.

\section{Fontes de dados para a construção dos indicadores}

Assembleia Legislativa do Estado de São Paulo (Alesp)

Fundação Sistema Estadual de Análise de Dados (Seade)

Instituto Brasileiro de Geografia e Estatística (IBGE)

Instituto Nacional de Estudos e Pesquisas Educacionais Anísio Teixeira (Inep)

Ministério do Desenvolvimento Social e Combate à Fome (MDS)

Ministério da Fazenda — Secretaria do Tesouro Nacional (STN)

Ministério da Saúde - Departamento de Informática do SUS (Datasus)

Ministério do Trabalho e Emprego (MTE)

Francisco Fonseca é mestre em ciência política e doutor em história, professor de ciência política da FGV/Eaesp e pesquisador do Centro de Estudos em Administração Pública e Governo (CEAPG) da FGV/ Eaesp. Foi coordenador do Prêmio "Municípios que Fazem Render Mais". E-mail: franciscocpfonseca@ gmail.com.

Ricardo Ernesto Vasquez Beltrão é mestre e doutorando em administração pública e governo pela FGV/ Eaesp. Pesquisador do Centro de Estudos em Administração Pública e Governo (CEAPG) da FGV/Eaesp. Foi pesquisador sênior do Prêmio "Municípios que Fazem Render Mais". E-mail: revbeltrao@yahoo. com.br.

Otávio Prado é doutor em administração pública e governo pela FGV/Eaesp e pesquisador do Centro de Estudos em Administração Pública e Governo (CEAPG) da FGV/Eaesp. Foi pesquisador sênior do Prêmio "Municípios que Fazem Render Mais". E-mail: otavioprado@gvmail.br. 